Portland State University

PDXScholar

$11-1986$

\title{
Body Size, Nest Predation, and Reproductive Patterns in Brown Thrashers and Other Mimids
}

\author{
Michael T. Murphy \\ Portland State University, murphym@pdx.edu \\ Robert C. Fleischer
}

Follow this and additional works at: https://pdxscholar.library.pdx.edu/bio_fac

Part of the Biology Commons, and the Ornithology Commons

Let us know how access to this document benefits you.

\section{Citation Details}

Murphy, M. T., \& Fleischer, R. C. (1986). Body size, nest predation, and reproductive patterns in Brown Thrashers and other mimids. Condor, 446-455.

This Article is brought to you for free and open access. It has been accepted for inclusion in Biology Faculty Publications and Presentations by an authorized administrator of PDXScholar. Please contact us if we can make this document more accessible: pdxscholar@pdx.edu. 


\title{
BODY SIZE, NEST PREDATION, AND REPRODUCTIVE PATTERNS IN BROWN THRASHERS AND OTHER MIMIDS ${ }^{1}$
}

\author{
Michael T. MurPhY ${ }^{2}$ AND Robert C. FleisCHER ${ }^{3}$ \\ Department of Systematics and Ecology, Museum of Natural History, \\ University of Kansas, Lawrence, KS 66045
}

\begin{abstract}
We describe the breeding biology of Brown Thrashers (Toxostoma rufum) in Kansas, and combine this with data from other temperate-zone breeding Mimidae to characterize reproductive patterns in this group. Brown Thrashers produced clutches of 3 to 6 eggs, but clutches of 4 predominated. Most pairs raised 2 broods per year. Incubation required between 13 and 14 days, and hatching was usually asynchronous. Though sample size was small, asynchrony appeared to increase in frequency towards the end of the breeding season. Nestlings grew rapidly, and in 10 days or less most pre-fledging growth was completed. Young fledged normally at 11 days of age at $65 \%$ of adult weight, but with the tarsi near adult size. Nestlings starved in $27 \%$ of nests, but predators were responsible for most nest failures. Overall nest success was $43 \%$.

Brown Thrashers are typical of other temperate-zone mimids. Modal clutch sizes are of either 3 or 4 eggs and all species are multi-brooded. Mimids from the southwestern United States and Mexico lay normally 3 egg clutches, but elsewhere 4 eggs are most common. Incubation length and nestling growth rate vary significantly with adult weight, but on average, incubation is 3 days shorter and nestlings grow $36 \%$ faster than predicted. Relative incubation length and relative fledging weight both declined significantly with adult weight, whereas daily nest mortality rate increased significantly with adult size. Although our data are consistent with the hypothesis that heavy nest predation has favored rapid nestling growth and completion of development outside of the nest, rapid growth may also function in brood reduction. Present data are insufficient to exclude conclusively either factor in the evolution of rapid development in mimids.
\end{abstract}

Key words: Brood reduction; growth; hatching asynchrony; Mimidae; nest predation; Toxostoma.

\section{INTRODUCTION}

Variability of growth rates and hatching patterns in altricial nestlings have been related chiefly to features of their food supply and the frequency of nest loss to predators. Growth rates determine peak nestling energy demand (O'Connor 1977, Ricklefs 1984) and time spent in the nest, thereby influencing both the parent's ability to eliminate starving young through brood reduction (O'Connor 1977), and the probability that predators will locate and destroy nests before fledging (Lack 1968, Ricklefs 1969a, 1984). Hatching asynchrony results in size differences among young which has traditionally been viewed as an adaptation to facilitate brood reduction (Lack 1954, Ricklefs 1965, Howe 1976, Richter 1984). It may also shorten exposure time for nest contents, and give the earliest hatching young growth advantages to increase their probabilities of escaping a predation attempt on the nest (Hussell 1972, Clark and Wilson 1981). Existing theory thus predicts the evolution of hatching asynchrony and rapid nestling growth in species

\footnotetext{
${ }^{1}$ Received 22 November 1985. Final acceptance 3 March 1986.

${ }^{2}$ Department of Life Sciences, Indiana State University, Terre Haute, IN 47809.

${ }^{3}$ Hawaiian Evolutionary Biology Program, University of Hawaii, 3050 Maile Way, 310 Gilmore, Honolulu, HI 96822.
}

either exploiting unpredictable food supplies, or suffering high rates of nest predation. Hatching asynchrony, however, possibly occurs for other reasons (Richter 1982, Clark and Wilson 1985, Hussell 1985, Mead and Morton 1985).

In this report we describe the breeding biology of Brown Thrashers (Mimidae: Toxostoma rufum) in eastern Kansas, including the first data on nestling growth. Aspects of their reproductive biology have been documented in a portion of their range (Erwin 1935), but only fragmentary information exists for Brown Thrashers breeding west of the Mississippi River (Gabrielson 1912, Johnston 1958). In conjunction with data on hatching and growth patterns, and sources of nestling mortality in other temperate-zone breeding mimids, we also describe and attempt to identify the selective basis for breeding patterns in this group.

One possible contributor to variability in reproduction is body size (Ricklefs 1968, Rahn et al. 1975, Blueweiss et al. 1978, Western and Ssemakula 1982, Calder 1984). Comparative breeding studies must therefore control for differences in size. Comparisons of allometric (i.e., size-dependent) relations of specific taxa to "average," empirically derived allometric relations are in fact preferable to single species comparisons because they are less subject to error. Our results suggest that reproductive patterns in mimids exhibit size dependence, but that a combination of ecological pressures 
have probably acted in concert to produce the characteristic mimid pattern of rapid nestling growth and short nest occupancy.

\section{METHODS}

\section{BROWN THRASHERS}

Field studies were conducted from the end of April through July, 1981 and 1982 in moderately grazed pasture located $6.5 \mathrm{~km}$ west of the city of Lawrence, Douglas County, Kansas $\left(38^{\circ} 57^{\prime} \mathrm{N}\right.$ and $\left.95^{\circ} 19^{\prime} \mathrm{W}\right)$. Scattered shrubs and trees were found throughout the site, but habitats with a closed canopy comprised less than $5 \%$ of the total area. Virtually all nests were located within an intensively studied area measuring about $740 \times 540 \mathrm{~m}$ (40 ha).

Nests were located by observing females in transit to either existing nests or those under construction. We visited nests every 2 to 3 days until eggs were laid, and then followed them until fledging of young or destruction of the nest. Dates of clutch initiation were obtained either by direct observation or by backdating from hatching date of clutches. Clutches observed during egg-laying were considered to be complete if successive visits indicated no change in egg number. Heavily incubated clutches were also assumed to be complete. Because eggs were always laid on successive days during laying, and because we had no evidence for egg removal by the brood-parasitic Brown-headed Cowbird (Molothrus ater), we assumed that clutches first observed during incubation represented full clutches. Nests that fledged at least one nestling were considered successful. We corrected nest success for exposure time using Mayfield's (1961) method.

Additional clutch size data were obtained from nest records at the University of Kansas Museum of Natural History (KUMNH, Lawrence, Kansas). For the nest records to be satisfactory for use, we required that successive visits had been made to each nest that indicated no change in egg number, or the observer noted that incubation was in progress. Only 38 of 98 nest records satisfied these criteria. We combined the nest record-card information with our field data and grouped nests into 15-day periods beginning 15 April to test for seasonal changes in clutch size. We also measured eggs for maximum length $(\mathrm{L})$ and breadth (B) in six nests in the field in 1981 and for 21 clutches previously collected in the same region and now located at the KUMNH. Volume was calculated as $0.51\left(\mathrm{~L} \times \mathrm{B}^{2}\right.$; Hoyt 1979), and then converted to weight by multiplying by egg density (= 1.09; Manning 1978).
A group of nests that survived incubation was used to measure nestling growth. Most nests were visited daily. Nestlings were identified by clipping toenails at the first visit. At the first and all subsequent visits, nestlings were weighed to the nearest $0.1 \mathrm{~g}$ (50 or $100 \mathrm{~g}$ Pesola Scale) and tarsus and eighth primary lengths measured to the nearest $0.1 \mathrm{~mm}$. Adult sizes were obtained from specimens in the KUMNH from eastern Kansas.

\section{INTERSPECIFIC STUDIES}

We restricted our analysis to species that breed in temperate-zone regions. Our sample included all 10 species of Mimidae breeding in North America, and one South American species. Due to varying degrees of completeness, sample sizes for different analyses varied. We treated Arizona and south Texas populations of Curvebilled Thrashers ( $T$. curvirostre) separately since adult body size, clutch and egg sizes, and nestling growth all showed distinct differences.

Adult weights were taken from original sources when given. Otherwise, we used Dunn's (1984) compilation, or the field records of associates to obtain weights for adults. Adult tarsus lengths were measured (nearest $0.1 \mathrm{~mm}$ ) from 5 male and 5 female specimens for each species with data on growth of the tarsus (study skins from the KUMNH). We estimated mean egg weight for each species using the egg measurements given in Bent (1948) and Fraga (1985), and the conversion factors described above for Brown Thrashers. This was justified by comparison of calculated egg weight to actual fresh egg weight for Crissal Thrashers $(T$. dorsale) and Chalk-browed Mockingbirds ( $M$. saturninus) given by Finch (1982) and Fraga (1985), respectively. In both cases, calculated and observed weights differed by less than $1 \%$. Clutch size, incubation and nestling period lengths, weight gain and tarsus growth, and nest success were taken from original literature sources. We used Bent's (1948) summaries for the former three variables only when data were not available from field studies.

Rates of nestling weight gain and increase in tarsus length were calculated for all species with data using Ricklefs' (1967) graphical method. Allometric relationships between body size (or egg size) and reproductive traits in mimids were described by applying least squares linear regression to double logarithmic transformations of each dependent variable versus body weight (or egg weight). Comparison of the mimid relationship to established allometric baselines (see below) were made by determining whether the $95 \%$ confidence intervals enclosing the mimid expression in- 
TABLE 1. Summary of the average weight (g), and tarsus and eighth primary lengths ( $\mathrm{mm}$ ) for nestling Brown Thrashers in eastern Kansas. Reported values are the mean, with the standard deviation and sample size in parentheses. Hatching is day 1 .

\begin{tabular}{rrrc}
\hline \hline \multicolumn{1}{c}{ Age } & Weight & Tarsus & Eighth primary \\
\hline Day 1 & $5.5(1.28 ; 19)$ & $8.3(0.84 ; 19)$ & - \\
2 & $9.2(1.50 ; 18)$ & $10.6(0.92 ; 21)$ & - \\
3 & $13.0(2.51 ; 19)$ & $12.5(1.73 ; 19)$ & $0.5(0.40 ; 15)$ \\
4 & $17.3(2.84 ; 12)$ & $15.0(2.13 ; 11)$ & $1.9(0.44 ; 8)$ \\
5 & $24.8(3.68 ; 21)$ & $20.3(1.75 ; 23)$ & $4.5(0.81 ; 9)$ \\
6 & $31.4(2.85 ; 14)$ & $24.0(1.38 ; 19)$ & $8.6(1.10 ; 10)$ \\
7 & $36.6(3.54 ; 14)$ & $27.2(1.17 ; 14)$ & $13.6(1.52 ; 10)$ \\
8 & $38.4(4.33 ; 16)$ & $29.1(1.76 ; 16)$ & $17.9(1.10 ; 9)$ \\
9 & $44.1(2.58 ; 15)$ & $31.7(2.05 ; 17)$ & $22.3(1.21 ; 10)$ \\
10 & $45.2(3.45 ; 8)$ & $32.9(1.42 ; 8)$ & $26.8(1.14 ; 4)$ \\
11 & $45.7(3.23 ; 3)$ & $34.3(0.59 ; 3)$ & - \\
Adult & $72.2(5.19 ; 18)$ & $35.0(0.85 ; 18)$ & \\
\hline
\end{tabular}

cluded the baseline allometric relationship for birds.

\section{RESULTS}

\section{BROWN THRASHERS}

Egg-laying extended from the latter third of April until the end of July. Two of three females that successfully fledged their first broods were known to have laid second clutches, and all females that failed in their first attempt laid replacement clutches. Most pairs probably attempt to raise two broods per year (see also Erwin 1935).

Clutch size averaged 4.1 eggs in both the field sample $(\mathrm{SD}=0.70, n=21$, range $=3$ 5 ) and the nest record cards $(\mathrm{SD}=0.74, n=$ 38 , range $=3-6$ ). Combining data sets, modal clutch size in Kansas was 4 eggs $(n=33)$, followed in decreasing order of abundance by clutches of $5(n=16), 3(n=9)$ and $6(n=1)$ eggs. Smaller average clutch size was reported by Porter (in Johnston 1958) from northern Kansas $(\bar{x}=3.5$ eggs, $n=51)$. We speculate that Porter included incomplete clutches, or nests that had suffered partial losses. Our overall mean for Kansas (4.1 eggs, SD $=0.68, n=$ 59) did not differ significantly $(t=1.55, \mathrm{df}=$ $107, P>0.20$ ) from the mean clutch size of Brown Thrashers in Tennessee $(\bar{x}=3.9, \mathrm{SD}=$ 66, $n=50$; Erwin 1935).

Early and late clutches in Kansas averaged 4.0 eggs $(\mathrm{SD}=0.72, n=32 ; 15$ April to 15 May, and 16 June through July). Though midseason clutches tended to be larger $(\bar{x}=4.3$ eggs, $\mathrm{SD}=0.63, n=27$; late May and early June), the difference between mid-season clutches and those laid at other times was not significant $(t=1.87, \mathrm{df}=57, P=0.07)$. Porter (Johnston 1958) reported that clutch size also peaked during the same period. Erwin (1935), however, reported a significant seasonal decline in clutch size in Tennessee, with no midseason peak.
Mean egg mass was $5.8 \mathrm{~g}(\mathrm{SD}=0.55, n=$ 27 clutches). Eggs measured in the field during 1981 were identical in size to eggs from the KUMNH $(\bar{x}=5.8 \mathrm{~g}, \mathrm{SD}=0.70, n=6$ nests and $\mathrm{SD}=0.44, n=21$ nests, respectively). Using an adult weight of $72.2 \mathrm{~g}$ for Brown Thrashers in Kansas (SD $=5.19 \mathrm{~g}, n=18$ ), and Rahn et al.'s (1975) prediction equation for passerines, predicted egg weight was $6.2 \mathrm{~g}$. This exceeded the observed mean in Kansas by about $7 \%$, but the difference was not significant $(t=0.71, \mathrm{df}=26, P>0.40)$.

The average length of incubation (time between the laying of the last egg and its hatching) was 13.6 days (SD $=0.55,3$ at 14 and 2 at 13), significantly longer than that reported by Erwin $(\bar{x}=12.6$ days, $\mathrm{SD}=0.71, n=17 ; t=$ 2.89 , df $=15, P<0.05)$. Though based on a small sample size, it appeared that hatching synchrony varied seasonally. Of six nests for which the pattern of hatching was determined, two early-season nests were synchronous, whereas four clutches hatched in the latter half of the season were all asynchronous (i.e., $>1$ day required for all eggs to hatch).

The nestling period averaged 11.6 days ( $\mathrm{SD}=0.89$ days, $n=5$, range $=11-13)$, in accordance with Erwin's (1935) reported mean of 11 days. Table 1 summarizes data on nestling weight gain and growth of the tarsus and eighth primary feather over this period. Average asymptotic weight $(A)$ and rate of weight gain $(K)$ were $47.9 \mathrm{~g}$ and 0.512 , respectively. Average values for the tarsus were $A=34.9$ $\mathrm{mm}$ and $K=0.444$. At fledging the tarsi were nearly adult length but weight was only at 65 to $70 \%$ of adult size (Table 1). The times required to grow between 10 and $90 \%$ of final fledging size $\left(\mathrm{t}_{10-90} ;\right.$ Ricklefs 1967$)$ were 8.6 and 9.9 days, respectively, for weight and tarsus length. Hence, in 10 days or less both variables were about fledging size, which for the tarsus was nearly adult size. 
TABLE 2. Summary statistics for reproductive traits in temperate-zone breeding Mimidae. All weights are in grams, and incubation length in days. Egg weights were taken from Bent (1948) except for Chalk-browed Mockingbirds. Egg weights were also available for catbirds, Brown Thrashers and Crissal Thrashers from field studies. These follow Bent's data, which is always the first listed under egg weight. Under source listings, KS, TX, and AZ refer to weights and breeding data for populations specific to Kansas, Texas and Arizona. For clutch size and incubation length, means are given outside of parentheses, followed by the standard deviation and sample size in the parentheses.

\begin{tabular}{|c|c|c|c|c|c|}
\hline Species & Body weight & Clutch size & Egg weight & Incubation length & Source \\
\hline Dumetella carolinensis & 36.2 & $\begin{array}{l}3.3(0.75 ; 22) \\
3.8(0.67 ; 73) \\
3.9(-; 37) \\
4.1(-; 314)\end{array}$ & 3.97 & $\begin{array}{l}\overline{13.4}(-; 30) \\
12.9(-;-) \\
-\end{array}$ & $\begin{array}{l}1 \\
2 \\
3 \\
4\end{array}$ \\
\hline Oreoscoptes montanus & 43.3 & $3.5(0.80 ; 38)$ & 4.47 & $15.0(1.3 ; 9)$ & 5 \\
\hline Mimus polyglottos & 48.5 & $3.9(0.61 ; 182)$ & 4.52 & $12-12.5^{*}$ & 6 \\
\hline M. saturninus & 78.7 & $3.6(0.76 ; 14)$ & 6.70 & 13.5 & 7 \\
\hline Toxostoma rufum & $\begin{array}{l}68.8 \\
72.2\end{array}$ & $\begin{array}{l}3.9(0.66 ; 50) \\
4.1(0.71 ; 59)\end{array}$ & $\begin{array}{l}5.54 \\
5.82\end{array}$ & $\begin{array}{l}12.6(0.71 ; 12) \\
13.6(0.55 ; 5)\end{array}$ & $\begin{array}{l}8 \\
9(\mathrm{KS})\end{array}$ \\
\hline T. longirostre & 69.9 & $3.4(0.80 ; 7)$ & 5.95 & $14.0(0.60 ; 3)$ & 10 \\
\hline T. curvirostre & $\begin{array}{l}84.5 \\
79.4\end{array}$ & $\begin{array}{l}3.8(0.50 ; 67) \\
3.0(0.58 ; 56) \\
2.8(0.56 ; 15)\end{array}$ & $\begin{array}{l}5.85 \\
6.27\end{array}$ & $\begin{array}{l}14.0(1.3 ; 18) \\
14\end{array}$ & $\begin{array}{l}10(\mathrm{TX}) \\
11(\mathrm{AZ}) \\
12(\mathrm{AZ})\end{array}$ \\
\hline T. dorsale & 62.7 & $3.0(-; 14)$ & $5.45,5.5$ & 14 & 13,11 \\
\hline T. bendirei & 62.2 & usually 3 & 5.19 & - & 11 \\
\hline T. lecontii & 61.9 & $3.1(0.68 ; 22)$ & 5.95 & $14-20$ & 14,11 \\
\hline T. redivivum & 86.4 & usually 3 & 7.52 & 14 & 11 \\
\hline
\end{tabular}

* - Incubation period underestimated by 1 day (see text).

Sources: 1-Zimmerman 1963; 2-Nickell 1965; 3-Johnson and Best 1980; 4-Crowell and Rothstein 1981; 5-Reynolds 1981; 6-Laskey 1962; 7Sources: 1 -Zimmerman 1963; 2-Nickell 1965; 3-Johnson and Best 1980; 4-Crowell and Rothstein 1981; 5-Reynolds 1981; 6-Laskey 1962; 7-
Fraga 1985 and Mason 1985; 8-Erwin 1935; 9-this study; 10-Fischer 1981; 11-Bent 1948; 12-Ricklefs 1965; 13-Finch 1982;14-Sheppard 1970.

The two extreme examples of weight gain are presented in Figure 1. Initial brood size was four young in both nests. In the earlyseason nest, all nestlings hatched on the same day, grew rapidly, approached an asymptotic weight by about day 10 and fledged on day 11 (Fig. 1). Their average rate of weight gain was $K=0.632\left(\mathrm{t}_{10-90}=7.0\right.$ days). Nestlings in the second nest hatched asynchronously towards the end of the breeding season. Weight gain was slower $\left(K=0.396, \mathrm{t}_{10-90}=11.1\right.$ days), and by days 7 and 8 the third and fourth hatched nestlings, respectively, died apparently of starvation. The fourth hatched nestling died despite being larger than the remaining birds (Fig. $1)$. Nestlings starved in 3 of 11 nests $(27.3 \%)$, all during the latter half of the nesting season. Overall, $10.8 \%$ of nestlings starved, and in all cases they were the last hatched nestling(s) in each nest.

Of 24 nests, $43.7 \%$ fledged at least one nestling (instantaneous mortality rate $=0.0291$, with a 28-day nest period). Daily mortality rate, M (Ricklefs 1969 b), was $2.96 \%$ /day. Erwin (1935) did not correct nest success for exposure time, but detected a similar probability of success (37.5\%). Nest predation accounted for $54 \%$ of nest failures in Kansas, followed by weather $(27 \%)$ and desertion (9\%). The cause for four nest failures was undetermined.

\section{INTERSPECIFIC COMPARISONS}

Body size and reproduction. All mimids have modal clutch sizes of either 3 or 4 eggs (Table 2). Clutch size and body weight were not sig- nificantly related $(r=-0.340, n=12, P \gg$ 0.05 ), but regional variation in clutch size appears to exist. Thrashers from the southwestern U.S. and Mexico (Toxostoma plus Oreoscoptes) lay fewer eggs per clutch $(\bar{x}=3.12$, $\mathrm{SD}=0.263, n=4)$ than mimids from elsewhere on the North American continent $(\bar{x}=$ $3.77, \mathrm{SD}=0.195, n=5)$. The difference is significant $(t=4.2, \mathrm{df}=7, P<0.01)$. Irrespective of location, all species are double- or occasionally triple-brooded.

Egg weight was a direct function of body size. Adult body weight accounted for $87 \%$ of the total variation in egg weight $(P<0.001$; Table $3)$. The $95 \%$ confidence limits completely enclosed the average regression line describing the relationship between adult weight and egg weight in passerines (Fig. 2), indicating no significant deviation from the average passerine relationship. Incubation length was less dependent on body size. In general, incubation length in birds correlates directly with adult body weight (Rahn and Ar 1974) and egg weight (Rahn et al. 1975, Western and Ssemakula 1982). The average length of incubation varied only between 13 and 15 days in mimids (Table 2), and was the longest in the Sage Thrashers (Oreoscoptes montanus), despite it being the second smallest species. Incubation length was not significantly correlated with either adult body weight $(r=0.163)$ or egg weight $(r=$ $0.216)$.

After excluding Sage Thrashers, however, significant relationships were found to exist between incubation length and both adult 


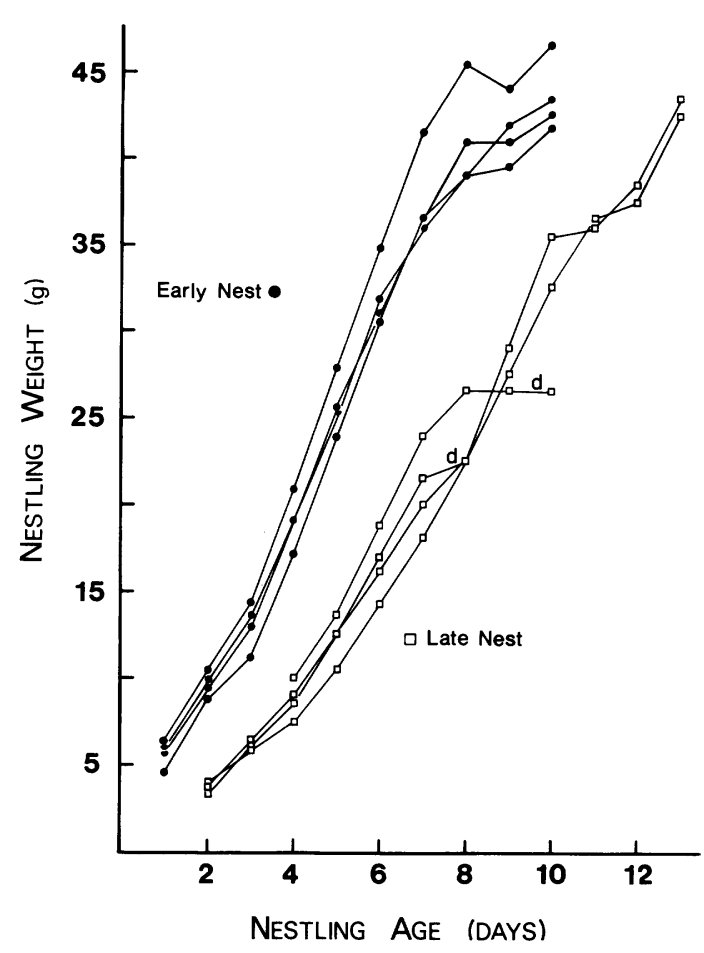

FIGURE 1. The pattern of weight change of nestling Brown Thrashers in an early (closed circle) and a late nest (open square) in Kansas in 1981. The d present on the growth curves of two nestlings from the late nest indicates their weights on the day prior to their disappearance from the nest. The late nest is displaced one day to the right to facilitate presentation.

weight and egg weight $(P<0.05$; Table 3$)$. In both cases, the exponents differed significantly from zero $(P<0.05)$, but were also below the exponents relating incubation length to either adult weight $(b=0.200$, Rahn and Ar 1974) or egg weight $(b=0.217$, Rahn et al. $1975 ; b=$ 0.200 , Western and Ssemakula 1982) in birds generally. In the former case, the difference between the exponent in mimids and other birds was significant $(P<0.05)$. We cannot explain the relatively long incubation period of Sage Thrashers, but suspect that environmental factors (e.g., low air temperature, as in Murphy 1983) lengthened the incubation period.

Rahn and Ar's (1974) equation provided the closest fit of observed to expected incubation length of the several possible prediction equations (see above). The differences between predicted and observed length averaged 2.9 days less than predicted $(\mathrm{SD}=0.82, n=9)$. The deviation from the predicted incubation length was significantly correlated with adult body weight $(r=0.909, \mathrm{Y}=-7.7+5.91[\log$. WEIGHT], $n=9, P<0.001)$. This was also true when Sage Thrashers were excluded $(r=$ $0.917, \mathrm{Y}=-5.9+4.99[\log$ WEIGHT], $P=$ $0.003)$. Hence, large species had relatively the shortest incubation periods.

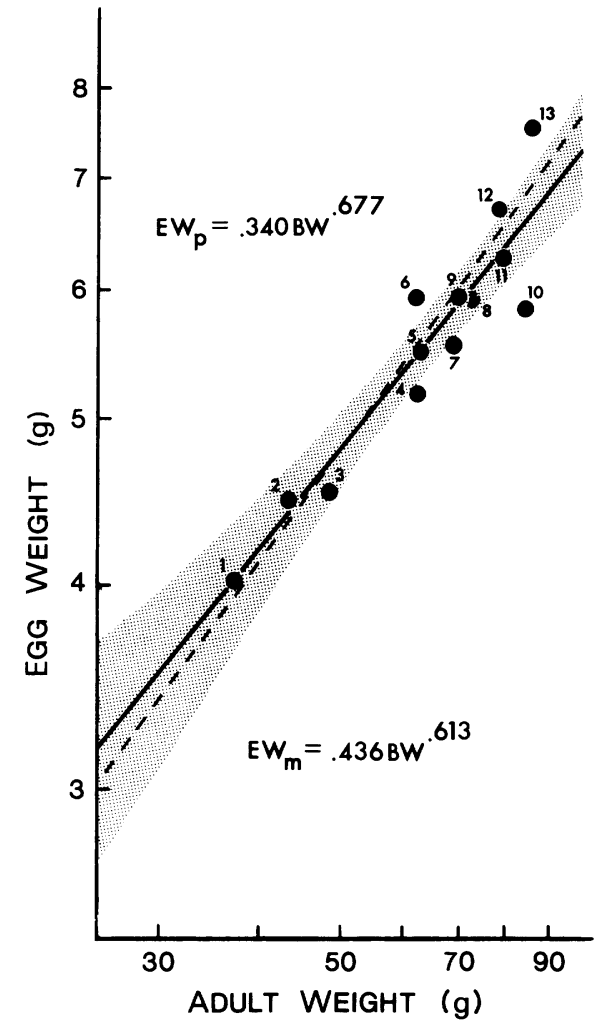

FIGURE 2. A log-log plot of the relationship between egg weight (EW) and adult body weight (BW) in temperatezone breeding mimids $\left(\mathrm{EW}_{\mathrm{m}}\right)$. The solid, heavy line represents this relationship, whereas the dashed line indicates the "average" pattern between egg weight and body weight in passerine birds $\left(\mathrm{EW}_{\mathrm{p}}\right.$; Rahn et al. 1975). The shaded region encloses the $95 \%$ confidence interval around the mimid relationship. Numbers 1 through 13, respectively, indicate Dumetella carolinensis, Oreoscoptes montanus, Mimus polyglottos, $T$. bendirei, $T$. dorsale, $T$. lecontii, $T$. rufum, T. rufum (Kansas), T. longirostre, $T$. curvirostre (Texas), T. curvirostre (Arizona), M. saturninus, T. redivivum.

The statistics of nestling growth are summarized in Table 4. Our measure of growth rate, $t_{10-90}$ (Ricklefs 1967), is an inverse measure of rate. Hence, large values indicate slow growth. Rate of weight gain varied significantly with adult body weight $(r=0.691)$, and asymptotic nestling weight $(r=0.691 ; P=0.04, n=$ $9)$. In neither of the equations relating growth rate to weight (Table 4) did the exponents differ significantly $(P \gg 0.05)$ from Ricklefs' (1968) empirically derived exponent describing the relationship between growth rate and asymptotic nestling weight in altricial birds $(b=$ 0.278 ).

However, the coefficient (Y-intercept) in Ricklefs' equation was $36 \%$ higher than the values we obtained using either adult or asymptotic weights (Fig. 3). The $95 \%$ confidence limits around the regression of rate of weight gain on asymptotic nestling weight for mimids (Fig. 3) did not include Ricklefs' (1968) allometric average for birds with altricial young, 
TABLE 3. Power equations of the form $\mathrm{Y}=\mathrm{aX}^{\mathrm{b}}$ and statistics describing variation in breeding traits in the Mimidae. The dependent variable $(\mathrm{Y})$ in each regression is given under Variable, followed by the independent variable $(\mathrm{X})$ in parentheses as follows: $\mathrm{BW}=$ adult weight, $\mathrm{EW}=$ egg weight, $\mathrm{AW}=$ asymptotic nestling weight, $\mathrm{WT}=$ rate of weight gain, and TR = rate of tarsus growth. Weights are all in $\mathrm{g}$ except for adult body weight under incubation length, which is in $\mathrm{kg}$.

\begin{tabular}{|c|c|c|c|c|c|c|c|}
\hline Variable & $n$ & $\mathrm{a}$ & $\mathrm{b}(95 \% \mathrm{CI})$ & $\overline{\mathrm{Y}}(95 \% \mathrm{CI})$ & $\bar{x}$ & $r^{2}$ & $P$ \\
\hline Egg weight (BW) & 13 & 0.436 & $\begin{array}{c}0.613 \\
(0.456-0.770)\end{array}$ & $\begin{array}{c}5.56 \\
(5.34-5.78)\end{array}$ & 64.0 & 0.872 & 0.001 \\
\hline Incubation (EW) & 8 & 11.06 & $\begin{array}{c}0.121 \\
(0.018-0.224)\end{array}$ & $\begin{array}{c}13.62 \\
(13.35-13.89)\end{array}$ & 5.59 & 0.563 & 0.035 \\
\hline Incubation (BW) & 8 & 17.26 & $\begin{array}{c}0.087 \\
(0.019-0.154)\end{array}$ & $\begin{array}{c}13.62 \\
(13.37-13.87)\end{array}$ & 0.065 & 0.605 & 0.025 \\
\hline Weight gain (AW) & 9 & 2.90 & $\begin{array}{c}0.306 \\
(0.027-0.585)\end{array}$ & $\begin{array}{c}9.24 \\
(8.63-9.90)\end{array}$ & 44.1 & 0.477 & 0.040 \\
\hline Weight gain (BW) & 9 & 3.29 & $\begin{array}{c}0.253 \\
(0.022-0.484)\end{array}$ & $\begin{array}{c}9.24 \\
(8.63-9.90)\end{array}$ & 59.3 & 0.477 & 0.040 \\
\hline Tarsus growth (BW) & 6 & 3.52 & $\begin{array}{c}0.268 \\
(0.005-0.531)\end{array}$ & $\begin{array}{c}10.30 \\
(9.48-11.19)\end{array}$ & 55.3 & 0.631 & 0.062 \\
\hline Nestling period (WT) & 7 & 2.75 & $\begin{array}{c}0.675 \\
(0.006-1.344)\end{array}$ & $\begin{array}{c}12.10 \\
(11.41-12.84)\end{array}$ & 9.01 & 0.549 & 0.059 \\
\hline Nestling period (TR) & 6 & 2.43 & $\begin{array}{c}0.689 \\
(0.139-1.239)\end{array}$ & $\begin{array}{c}12.12 \\
(11.43-12.85)\end{array}$ & 10.3 & 0.722 & 0.036 \\
\hline
\end{tabular}

Column headings starting with $n$ are: sample size, Y-intercept, regression coefficient ( $95 \%$ confidence limits below), mean of the dependent variable ( $95 \%$ Column headings starting with $n$ are: sample size, $Y$-intercept, regression coefficient ( $95 \%$ confidence limits below), mean of the independent variable, coefficient of determination, probability level.
confident

indicating that nestling mimids grew faster than expected based on size.

Tarsus growth rate also scaled to adult body weight with about the same exponent $(b=$ 0.270 ; Table 3 ). The relationship only approached significance $(r=0.796, P=0.062$, $n=6)$. The larger coefficient for tarsus growth indicates relatively slower growth compared to weight, despite the fact that the young fledged with their tarsi at about adult size (Table 4). Presumably, this reflects the fact that the tarsi were relatively much closer to adult size at hatching than was weight (e.g., Table 1).

Relative weights at fledging $\left(R_{w}\right)$ were all fairly low (Table 4; compare to Ricklefs 1968).
$\mathrm{R}_{\mathrm{w}}$ appeared to vary inversely with adult weight. A test of association between $R_{w}$ and adult weight using Kendall's coefficient of rank correlation indicated that $R_{w}$ varied significantly with adult weight (tau $=0.61, P<0.05$ ). Nestlings of large mimids (i.e., $>60 \mathrm{~g}$ adult weight) thus fledged relatively lighter than nestlings of the small species $(<50 \mathrm{~g})$. This was not true of $R_{t}$, the ratio of asymptotic to adult tarsus length. $R_{t}$ was at or near 1.0 in all species by the time of fledging (Table 4).

Hatching patterns, starvation, and nest success. Data on hatching asynchrony and the occurrence of nestling starvation were not available for all species (Table 5). Of the 9 species

TABLE 4. Growth rates $\left(K, \mathrm{t}_{10-90}\right)$, asymptotic sizes $(A)$ and the ratios $(R)$ of nestling size at fledging to adult size for weight $(\mathrm{g})$ and tarsus length $(\mathrm{mm})$ in nestling mimids. Nestling period length is given in days. Values for weight gain are above and outside of parentheses, whereas those for tarsus growth are below and within the parentheses.

\begin{tabular}{|c|c|c|c|c|c|c|c|}
\hline Species & Adult size & $A$ & $K$ & $t_{10-90}$ & $R$ & $\begin{array}{l}\text { Nestling } \\
\text { period }\end{array}$ & Source \\
\hline Dumetella carolinensis & $\begin{array}{c}36.2 \\
(24.0)\end{array}$ & $\begin{array}{c}28.0 \\
(23.0)\end{array}$ & $\begin{array}{c}0.549 \\
(0.468)\end{array}$ & $\begin{array}{c}8.0 \\
(9.6)\end{array}$ & $\begin{array}{c}0.77 \\
(0.96)\end{array}$ & 11 & $\begin{array}{l}1 \\
1\end{array}$ \\
\hline Oreoscoptes montanus & $\begin{array}{c}40.1 \\
(30.5)\end{array}$ & $\begin{array}{c}34.1 \\
(33.2)\end{array}$ & $\begin{array}{c}0.543 \\
(0.468)\end{array}$ & $\begin{array}{c}8.0 \\
(9.4)\end{array}$ & $\begin{array}{c}0.85 \\
(1.0)\end{array}$ & 12 & $\begin{array}{l}2 \\
2\end{array}$ \\
\hline Mimus polyglottos & $\begin{array}{c}47.7 \\
50.0 \\
(33.3)\end{array}$ & $\begin{array}{c}39.1 \\
37.5 \\
(32.2)\end{array}$ & $\begin{array}{c}0.452 \\
0.492 \\
(0.452)\end{array}$ & $\begin{array}{c}9.7 \\
8.9 \\
(9.7)\end{array}$ & $\begin{array}{c}0.82 \\
0.75 \\
(0.97)^{*}\end{array}$ & 12 & $\begin{array}{l}3 \\
4 \\
3\end{array}$ \\
\hline M. saturninus & 78.7 & 61.6 & 0.476 & 9.2 & 0.78 & 12 & 5 \\
\hline Toxostoma longirostre & $\begin{array}{c}67.7 \\
(36.5)\end{array}$ & $\begin{array}{c}49.9 \\
(35.2)\end{array}$ & $\begin{array}{c}0.443 \\
(0.408)\end{array}$ & $\begin{array}{c}9.9 \\
(10.8)\end{array}$ & $\begin{array}{c}0.73 \\
(0.96)^{*}\end{array}$ & 13 & $\begin{array}{l}3 \\
3\end{array}$ \\
\hline T. rufum & $\begin{array}{c}72.2 \\
(35.0)\end{array}$ & $\begin{array}{r}47.9 \\
(34.9)\end{array}$ & $\begin{array}{c}0.512 \\
(0.444)\end{array}$ & $\begin{array}{c}8.6 \\
(9.9)\end{array}$ & $\begin{array}{c}0.66 \\
(1.0)\end{array}$ & 11 & $\begin{array}{l}6 \\
6\end{array}$ \\
\hline T. curvirostre & $\begin{array}{c}79.7 \\
84.5 \\
(34.5)\end{array}$ & $\begin{array}{c}55.0 \\
55.6 \\
(33.5)\end{array}$ & $\begin{array}{c}0.384 \\
0.444 \\
(0.344)\end{array}$ & $\begin{array}{r}11.5 \\
9.9 \\
(12.8)\end{array}$ & $\begin{array}{c}0.69 \\
0.65 \\
(0.97)^{*}\end{array}$ & $\overline{14}$ & $\begin{array}{l}7 \\
3 \\
3\end{array}$ \\
\hline
\end{tabular}

* Fischer (1983) obtained lower values for R, presumably because of slight differences in our technique for measuring tarsus length.
Sources: 1-Zimmerman 1963; 2-Killpack 1970; 3-Fischer 1983; 4-Breitwisch et al. 1984; 5-Fraga 1985; 6-this study; 7-Ricklefs 1965. 


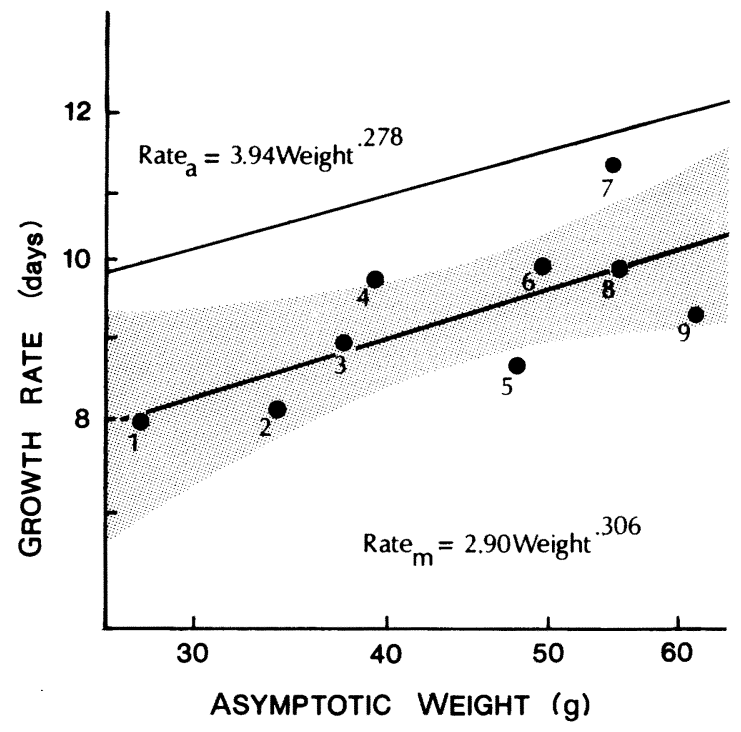

FIGURE 3. The rate of nestling weight gain $\left(t_{10-90} ;\right.$ Ricklefs 1967) plotted against asymptotic nestling weight of temperate-zone breeding mimids. The lower, heavy line describes the relationship in mimids $\left(\right.$ Rate $\left._{m}\right)$, whereas the upper line represents the "average" pattern for birds with altricial young (Rate ${ }_{a}$; Ricklefs 1968 ). The shaded region represents the $95 \%$ confidence region around the mimid relationship. Numbers 1 through 9 , respectively, indicate Dumetella carolinensis, Oreoscoptes montanus, Mimus polyglottos (from Texas), M. polyglottos (from Florida), Toxostoma rufum, T. longirostre, T. curvirostre (Arizona), T. curvirostre (Texas), M. saturninus.

for which information on hatching patterns was found, 7 reported asynchrony to be common, especially in large clutches. Starvation was not as well documented. For the seven species with data, starvation occurred frequently in three, was absent in two others, and in both the Gray Catbird (Dumetella carolinensis) and Curvebilled Thrasher was reported to be common in one study yet essentially absent in another (Table 5). When starvation was reported, about $25 \%$ of all nests were affected (Table 5 ).
The percentage of nests which successfully fledged young varied from $26 \%$ to $70 \%$. To compare species for differences in the rate of nest loss we calculated the average proportion (unweighted) of successful nests for each species, and converted it to average daily nest mortality rate (Ricklefs 1969b). A regression of average daily nest mortality rate (NMR) on the logarithm of adult weight yielded a significant positive relationship $(r=0.727, n=8$, $P=0.04 ;$ NMR $=-0.069+0.0559[\log -$ WEIGHT]. To our knowledge, these are the first data for any passerine family demonstrating a correlation between body size and reproductive success.

\section{DISCUSSION}

Breeding patterns of Brown Thrashers in Tennessee and Kansas were very similar. The only apparent differences between Erwin's (1935) study and ours were that incubation was significantly shorter in Tennessee, and that clutch size declined seasonally in Tennessee but not in Kansas. The difference in incubation length seemed likely to have arisen from methodological differences in the determination of length. Whereas we counted incubation from the end of egg-laying to hatching of the last egg, Erwin probably counted to the hatching of the first egg. The difference in seasonal variation in clutch size was probably artifactual since a definite trend existed for late clutches to be smaller in Kansas. Small sample size rather than intrinsic population differences probably account for this discrepancy.

Breeding patterns among temperate-zone mimids were also quite uniform. Our emphasis on relating reproductive traits to body size clearly showed that much of the observed interspecific variability in certain traits was due to differences in body size. However, our

TABLE 5. Hatching patterns, observations on nestling starvation, and nest success for mimids breeding in temperatezone regions. Asyn and Syn refer to asynchronous and synchronous hatching, respectively. Percentages under starvation refer to the percentage of nests with nestlings that experienced starvation. Under nest success, the numbers indicate the percentage of nests that fledged at least one nestling. Numbers in parentheses following data indicate sources.

\begin{tabular}{|c|c|c|c|}
\hline Species & Hatch pattern & Nestling starvation & Nest success \\
\hline Dumetella carolinensis & Asyn $(1,2)$ & $\begin{array}{l}\text { Very low }(3) \\
\text { Present }(15.1 \% ; 4)^{*}\end{array}$ & $\begin{array}{l}58(1), 70(4) \\
69(5), 44(6)\end{array}$ \\
\hline Mimus polyglottos & Unknown & Absent (7) & $56(7)$ \\
\hline$M$. saturninus & Asyn (8) & Present $(20.0 \% ; 8)$ & $27(8)$ \\
\hline Oreoscoptes montanus & Syn (9) & Present $(\sim 30 \% ; 9)$ & $45(9)$ \\
\hline Toxostoma rufum & Asyn (10) & Present $(27.3 \% ; 10)$ & $44(10), 37(11)$ \\
\hline$T$. longirostre & Syn (7) & Absent (7) & $26(12)$ \\
\hline T. curvirostre & Asyn (7) & Absent (7) & $37(12)$ \\
\hline & Asyn (13) & Present (?; 13) & Unknown \\
\hline$T$. dorsale & Asyn $(2,14)$ & Unknown & $48(14)$ \\
\hline$T$. lecontii & Asyn (15) & Unknown & Unknown \\
\hline
\end{tabular}

* The figure of $15.1 \%$ refers to percentage of nestlings that starved. A higher value would occur if expressed in relation to number of nests. 1983; 8-Fraga 1985; 9-Reynolds 1981; 10-this study; 11-Erwin 1935; 12-Fischer 1981; 13-Ricklefs 1965; 14-Finch 1982; 15-Sheppard 1970 
method of analysis also highlighted a number of unambiguous trends in the data indicating that ecological factors have significantly influenced the evolution of life histories in the Mimidae.

Clutch size, for example, was independent of body size yet did vary with geographic distribution. All species were multibrooded, and laid normally 3 to 4 eggs per clutch. Mimids of the arid southwestern U.S. and Mexico, however, produced smaller clutches than species breeding elsewhere. This was evident even within Curve-billed Thrashers (Table 2). Nestling Curve-billed Thrashers from Arizona also showed the slowest relative growth rate of all species in the sample (Fig. 3). The small average clutch size of these species, and the heavy nestling starvation in Curve-billed Thrashers from Arizona (Ricklefs 1965), but not Texas (Fischer 1983), suggest that the rate at which offspring can be supplied with food is limited in desert environments. This may be due either to low habitat productivity (Rosenzweig 1968) or limitation of adult activity by thermal stresses (e.g., Calder 1968, Ricklefs and Hainsworth 1968, Austin 1976, 1978).

The strongest pattern, however, was the consistent trend for rapid development of both embryos and nestlings, and the generally short periods of nest occupancy. Incubation length did not scale closely to body size in our sample, due mainly to the long incubation period of Sage Thrashers. In all species, however, incubation was shorter than expected based on either adult size or egg weight. Relative incubation length also decreased significantly as body size increased, hence, the large species had the shortest relative lengths of incubation. Nestling growth rate was dependent on body size, but nestlings nonetheless grew significantly faster than expected. Growth patterns were such that young fledged at only $60 \%$ to $80 \%$ of adult weight, but with the tarsi always near adult size. Relative weight at fledging also decreased as adult body size increased, indicating that the young of the large species fledged at relatively earlier stages of development than the offspring of small species.

These data, and the finding that daily nest mortality rate rose significantly as adult body size increased, suggest strongly that minimization of the time spent in the nest exposed to predators as vulnerable eggs or nestlings is extremely important for mimid reproductive success. In accordance, predation was the major cause of nest failure in all the studies cited in Table 5 (see also Biedenweig 1983), except for Arizona Curve-billed Thashers (Ricklefs 1965). Our findings are therefore in agreement with Fischer's (1983) proposal that heavy nest predation in mimids favors short nest occupancy and completion of growth outside of the nest. Emphasis on leg growth and the attainment of functional maturity of the legs of nestlings ensures that early fledging is possible, especially in ground-foraging birds. Chalkbrowed Mockingbird nestlings, for example, can successfully fledge at 9 days of age if disturbed by predators, though nest departure normally occurs 3 to 5 days later (Fraga 1985). Dark-eyed Juncos (Junco hyemalis) also experience heavy nest predation, and exhibit very similar growth patterns (Smith and Andersen 1982; see also Austin and Ricklefs 1977).

We suspect, however, that other factors have also contributed to the evolution of nestling mimid growth patterns. For example, hatching asynchrony is typical of most mimids, and along with rapid nestling growth, comprise the essential components of the brood reduction strategy (O'Connor 1977). This paradigm proposes that when parents are faced with poor food supplies that are temporally stable, starving nestlings should be eliminated rapidly to avoid feeding young that are destined to die (O'Connor 1977). Hatching asynchrony produces size differences that are quickly accentuated by rapid growth. In this regard, rapid growth is critical because it increases nestling energy demands (Ricklefs 1984) and maximizes intrabrood competition, which eventually kills the starving offspring. Patterns of nestling starvation that conform to the brood reduction model have been observed in Curvebilled Thrashers (Ricklefs 1965), Chalk-browed Mockingbirds (Fraga 1985) and Brown Thrashers (this study). Gabrielson's (1912) observations on the distribution of food to four nestling Brown Thrashers also match predictions of the brood reduction model in that the smallest nestling received significantly fewer feeds than expected by chance $(n=878$ feedings, $\mathrm{G}=11.7, \mathrm{df}=3, P<0.01$ ).

Thus, rapid nestling growth (and hatching asynchrony) in Brown Thrashers, and possibly other mimids, may also function in brood reduction. Though nestling starvation is less common than nest predation among mimids, the variable occurrence of starvation may itself reflect the temporally and/or spatially variable nature of food supplies. At present, we cannot identify which, if either, of these models (nest predation vs. brood reduction) is primarily responsible for the pattern of rapid embryo and nestling growth that we have detected. We feel it is likely that both have contributed to the evolution of nestling mimid growth patterns. This conclusion, though unsatisfying from the standpoint of clean hypothesis testing, perhaps more realistically reflects the multiple selective 
pressures impinging on individual reproductive success. We suspect that many groundforaging birds (which nest close to the ground and frequently experience heavy nest predation), face similar selection pressures, and exhibit patterns similar to those found in the $\rightarrow$ Mimidae.

Clearly, more data and experimental tests of these ideas are necessary. Information is needed on hatching patterns, nestling growth, and rates of starvation in all species, but especially for mimids of the deserts of southwestern North America. It would be instructive also to determine whether food supplies, hatching patterns, the frequency of nestling starvation, and predator activity covary on either an annual or seasonal basis (Mead and Morton 1985, this study). Such information may allow discrimination between the several hypotheses tha $\rightarrow$ have been proposed to account for the evolution of hatching asynchrony and nestling growth rates in passerine birds.

\section{SUMMARY}

Our analysis of reproduction in Browr Thrashers and other temperate-zone breeding mimids leads us to conclude that (1) body size accounts for much of the interspecific variability in certain reproductive traits, but that ${ }^{+}$ (2) ecological pressures have selected for distinct patterns, including rapid development of embryos and nestlings. We suggest that both frequent loss of nests to predators, and unpredictable (but stable) food supplies have favored the evolution of the rapid developmental rates that characterize temperate-zone Mimidae. Hatching asynchrony is also common in mimids, and appears to function in brood reduction. Further data, and tests of these hypotheses are necessary, particularly in deser species.

\section{ACKNOWLEDGMENTS}

We are grateful to Louis Best, Richard Johnston, Jay Sheppard, and Peter Stacey for commenting on different versions of this manuscript. Louis Best in particular pointed out the previous early work on Brown Thrashers. John L. Zimmerman and an anonymous reviewer sharpened our interpretation of the data. We are appreciative for all $\mathrm{o}^{-}$ their contributions.

\section{LITERATURE CITED}

$\rightarrow$ Austin, G. T. 1976. Behavioral adaptations of the Ver $\rightarrow$ din to the desert. Auk 93:245-262.

$\rightarrow$ Austin, G. T. 1978. Daily time budget of the postnesting Verdin. Auk 95:247-251.

Austin, G. T., AND R. E. RickLefs. 1977. Growth and development of the Rufous-winged Sparrow (Aimophila carpalis). Condor 79:37-50.

BENT, A. C. 1948 . Life histories of North American nuthatches, wrens, thrashers and their allies. U.S. Natl $\rightarrow$ Mus. Bull. 195.
Best, L. B., AND D. F. StaufFer. 1980. Factors affecting nesting success in riparian bird communities. Condor 82:149-158.

BiedenWEG, D. W. 1983. Time and energy budgets of the Mockingbird (Mimus polyglottos) during the breeding season. Auk 100:149-160.

Blueweiss, L., H. Fox, V. Kudzma, D. Nakashima, R. Peters, AND S. SAMS. 1978. Relationships between body size and some life history parameters. Oecologia (Berl.) 37:257-272.

Breitwisch, R. P. G. Merritt, ANd G. H. Whitesides. 1984. Why do Northern Mockingbirds feed fruit to their nestlings? Condor 86:281-287.

CAlder, W. A. 1968. The diurnal activity of the roadrunner, Geococcyx californianus. Condor 70:84-85.

CAlder, WM. A., III. 1984. Size, function and life history. Harvard Univ. Press, Cambridge, MA.

Clark, A. B., AND D. S. Wilson. 1981. Avian breeding adaptations: hatching asynchrony, brood reduction and nest failure. Q. Rev. Biol. 56:253-277.

Clark, A. B., AND D. S. Wilson. 1985. The onset of incubation in birds. Am. Nat. 125:603-611.

Crowell, K. L., AND S. I. Rothstein. 1981. Clutch sizes and breeding strategies among Bermudan and North American passerines. Ibis 123:42-50.

DunN, J. B., III. 1984. Body weights of 686 species of North American birds. Western Bird-Banding, Monogr. No. 1.

Erwin, W. G. 1935. Some nesting habits of the Brown Thrasher. J. Tenn. Acad. Sci. 10:179-204.

FinCH, D. H. 1982. Rejection of cowbird eggs by Crissal Thrashers. Auk 99:719-724.

FISCHER, D. H. 1981. Breeding biology of Curve-billed Thrashers and Long-billed Thrashers in southern Texas. Condor 82:392-397.

FisCheR, D. H. 1983. Growth, development, and food habits of nestling mimids in south Texas. Wilson Bull. 95:97-105.

FraGA, R. M. 1985. Host-parasite interactions between Chalk-browed Mockingbirds and shiny cowbirds. Ornithol. Monogr. No. 36, American Ornithologists' Union, Washington, DC.

Gabrielson, I. N. 1912. A study of the home life of the Brown Thrasher, Toxostoma rufum (Linn.). Wilson Bull. 24:65-94.

Howe, H. F. 1976. Egg-size, hatching asynchrony, sex and brood reduction in the Common Grackle. Ecology 57:1195-1207.

Hoyt, D. F. 1979. Practical methods of estimating volume and fresh weight of bird eggs. Auk 96:73-77.

Hussel, D.J.T. 1972. Factors affecting clutch size in arctic passerines. Ecol. Monogr. 42:317-364.

HUSSELL, D.J.T. 1985. Optimal hatching asynchrony in birds: comments on Richter's critique of Clark and Wilson's model. Am. Nat. 126:123-128.

Johnson, E. J., AND L. B. BEST. 1980. Breeding biology of the Gray Catbird in Iowa. Iowa State J. Res. 55: 171-183.

Johnson, E. J., AND L. B. Best. 1982. Factors affecting feeding and brooding of Gray Catbird nestlings. Auk 99:148-156.

Johnston, R. F. 1958. Breeding of the Brown Thrasher in Kansas. Bull. Kansas Ornithol. Soc. 9:17-18.

KENDEIGH, S. C. 1942. Analysis of losses in the nesting of birds. J. Wildl. Manage. 6:19-26.

KILLPACK, M. L. 1970. Notes on Sage Thrasher nestlings in Colorado. Condor 73:486-488.

LACK, D. 1954. The natural regulation of animal numbers. Oxford Univ. Press, London.

LACK, D. 1968. Ecological adaptations for breeding in birds. Methuen, London.

LASKey, A. R. 1962. Breeding biology of Mockingbirds. Auk 79:596-600. 
$\rightarrow$ ManNing, T. H. 1978. Measurements and weights of eggs of the Canada Goose, Branta canadensis, analyzed and compared with those of other species. Can. J. Zool. 56:676-687.

MASON, P. 1985. The nesting biology of some passerine: of Buenos Aires, Argentina. Ornithol. Monogr. No 36, American Ornithologists' Union, Washington, DC.

$\rightarrow$ Mayfield, H. 1961. Nesting success calculated from exposure. Wilson Bull. 73:255-261.

$\rightarrow$ Mead, P. S., AND M. L. MoRTon. 1985. Hatching asynchrony in the Mountain White-crowned Sparrow (Zonotrichia leucophrys): a selected or incidental trait? Auk 102:781-792.

MURPHY, M. T. 1983. Ecological aspects of the reproductive biology of Eastern Kingbirds: geographic comparisons. Ecology 64:914-928.

NiCKeLL, W. P. 1965. Habits, territory, and nesting of the catbird. Am. Midl. Nat. 73:433-478.

O'CoNNOR, R. J. 1977. Growth strategies in nestling passerines. Living Bird 16:209-238.

pHN, H. AND A. AR. 1974. The avian egg: incubatior $\rightarrow$ time and water loss. Condor 76:147-152.

$\rightarrow$ Rahn, H., C. V. Pagnelli, ANd A. Ar. 1975. Relatior to avian egg weight to body weight. Auk 92:750-765.

ReYnolds, T. D. 1981. Nesting of the Sage Thrasher Sage Sparrow and Brewer's Sparrow in southeasterr Idaho. Condor 83:61-64

RICHTER, W. 1982. Hatching asynchrony: the nest-failure hypothesis and brood reduction. Am. Nat. 120 828-832.

RICHTER, W. 1984. Nestling survival and growth in the Yellow-headed Blackbird, Xanthocephalus xanthocephalus. Ecology 65:597-608.
RiCKLEFS, R. E. 1965. Brood reduction in the Curvebilled Thrasher. Condor 67:505-510.

RiCKLEFS, R. E. 1967. A graphical method of fitting equations to growth curves. Ecology 48:978-983.

Ricklefs, R. E. 1968. Patterns of growth in birds. Ibis 110:419-451.

Rickiefs, R. E. 1969a. Preliminary models for growth rates of altricial birds. Ecology 50:1031-1039.

RiCKLEFs, R. E. 1969b. Patterns of mortality in the nesting of birds. Smithson. Contrib. Zool. 9:1-48.

RICKLEFS, R. E. 1984. The optimization of growth rate in altricial birds. Ecology 65:1602-1616.

RickleFs, R. E., AND F. R. Hainsworth. 1968. Temperature dependent behavior of the Cactus Wren. Ecology 49:227-233.

ROSENZWEIG, M. L. 1968. Net primary productivity of terrestrial communities: predictions from climatological data. Am. Nat. 102:67-74.

Sheppard, J. M. 1970. A study of LeConte's Thrasher. Calif. Birds 1:85-94.

ACK, R. D. 1976. Nest guarding behavior by male Gray Catbirds. Auk 93:292-300.

Smith, K. G., AND D. C. Andersen. 1982. Food, predation and reproductive ecology of the Dark-eyed Junco in northern Utah. Auk 99:650-661.

WeSTeRn, D., AND J. Ssemakula. 1982. Life history patterns in birds and mammals and their evolutionary interpretations. Oecologia (Berl.) 54:281-290.

ZimMERMAN, J. L. 1963. A nesting study of the catbird in southern Michigan. Jack-Pine Warbler 41:142-160.

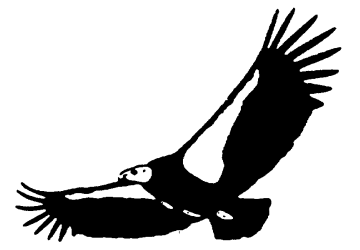

\section{IS A LIFE MEMBERSHIP A GOOD INVESTMENT?}

The Cooper Society recently reinstated the Life Membership category. Your $\$ 600$, paid in 4 installments or one lump sum, adds to our endowment managed by the Investing Trustees. The income generated will support publication of The Condor. Your life membership is an excellent investment in and for the Society: it increases value of the Endowment Fund, thus defraying costs that otherwise must be covered by annual dues. If each member had to pay his or her share of actually nunning the Society, dues would be more than $\$ 40$ per year. By investing in a Life Membership, you facilitate a broad membership, the continued vitality of the Society, and world-wide circulation of our scientific publication.

Since you are also concerned with your personal economics, consider that with the present $\$ 18$ annual dues, you would break even with a life membership in 34 years. Of course, dues will increase over the years, greatly shortening the break-even period. For most ornithologists, a life membership will protect you against future dues increases, and during your lifetime will be a bargain.

Gifts and bequests to the Society also are invested. If you wish to make $a$ gift or to mention the Society in your will, feel free to contact any Officer, or C. John Ralph, Endowment Fund-Raising Committee, 7000 Lanphere Road, Arcata, California 95521 (707) 822-3691 or $822-2015$ 